\title{
Research on Evolution Mechanism of Technological Original Innovation-With Mutation Theory of Respective
}

\author{
Zhi-Ming Zhu' ${ }^{1}$ Jin-Sheng Li $^{2}$, Tao Chen ${ }^{3}$ \\ ${ }^{1}$ School of Business, Hohai University, Nanjing, China; ${ }^{2}$ School of Business, Nanjing Normal University, Nanjing, China; ${ }^{3}$ School of \\ Management, Harbin Institute of Technology, Harbin, China. \\ Email: zhimingzhu@126.com
}

Received November $5^{\text {th }}, 2011$; revised December $17^{\text {th }}, 2011$; accepted December $29^{\text {th }}, 2011$

\begin{abstract}
Technical innovation is the power and resource for the sustainable and healthy development of enterprises, and is related to the improvement of social productivity and the establishment and improvement of national innovation system. Technical innovation is the process of the enterprise using the original knowledge and transforming it into new technology. The input and output of knowledge of (i.e., creating new technology) presents S curve, experiencing the stage of imitating type, fusion type and original type, which is subjected to the synergistic action of institutional arrangements factor and its operating factors. Through the analysis of evolution mechanism of different stages of technological innovation stages, this paper verifies the rationality and scientific nature of the theoretical assumptions.
\end{abstract}

Keywords: Original Innovation; Mutation Theory; Synergistic Action; Evolution Mechanism

\section{Introduction}

With the development of science and technology, economic globalization, the competition between enterprises is becoming increasingly fierce, and enterprise's technical original innovation ability is raised to a new level. It is the enterprise survival the primary motivation source of enterprises' future sustainable and healthy development, relating to promote and perfect the country and regional productivity development level. Technology for original innovation means that enterprises is at its most directly status in terms of owning and mastering knowledge, and have the final right to the knowledge property and its related interests. The development of technology and the improvement of enterprises need enterprises to evaluate and recognize its own innovation capacity to determine its own competitive advantages with the aim to transform new knowledge into new technology, improve enterprises efficiency and performances. The process of technological original innovation evolution ability is the most interesting problem of politicians and researchers from every country and region. How to improve enterprises original innovation ability and how to understand the concrete influencing factors of original innovation ability is always a key issue for people.

The following points of views are related to technological original evolution process.

1) Knowledge innovation theory. This theory emphasizes knowledge is more useful to technological original innovation. Haider put forward that the stock of knowledge influences enterprises technological innovation, and enterprise may offset knowledge gap to promote innovation (Haider, 2003) [1]. Enterprise innovation pathway presents different features in different enterprises with different technical levels and mainly embodies in the innovation of product and process performance (Kirner, et al., 2009) [2]. The establishment of knowledge innovation system needs gradually diminishing their knowledge necessary gaps, and decreasing path dependence on the outside of the elimination to absorb external useful knowledge for enterprise development and transform it into practical technological capacity; the combination of knowledge management system and technological innovation system is helpful to the realization of technological original innovation; the network and spread of knowledge can promote the accumulation of technological original innovation ability; the function of knowledge introductory and knowledge accumulation in technological original innovation can further improve the mechanism revolution of knowledge management on original innovation mechanism. The evolution of enterprise organization structure from the traditional mechanical organization to organic type realizes the network organization management, which can improve knowledge management systematization, and networking. That is more useful to technological original innovation.

2) Enterprises agglomeration theory. This theory em- 
phasizes enterprise clusters agglomeration helps to the communication and diffusion of technology from different types of enterprises. Enterprises within high technology clusters promote technical original innovation in strengthening technology competition (Malmberg, 2001) [3]. High technology industry cluster can promote enterprises to improve the ability of independent innovation, and obtain the industrial clusters' sustainable development power (Nunzia, 2004) [4]. Tsai and Wang investigated the Taiwan low- and medium-technology firms, and obtain external knowledge construction of $20 \%, 18 \%, 8 \%$ and $23 \%$ through the cooperation of suppliers, customers, competitors and research institutes (Tsai and Wang, 2009) [5]. Enterprise cluster can share some knowledge from different types of enterprises, construct shared systems, rules and procedures, coordinate knowledge absorption and diffusion necessary to the technological original innovation process, and can reduce the socialization process of knowledge transaction cost. The technological original innovation ability integrates the knowledge and resources within the process of the formation of enterprises cluster of enterprises, which consists of the enterprises innovation culture and ability and gradually accumulates inner resource endowment and external incentive mechanism.

3) Enterprises financing theory. This theory emphasizes the important role of investment capital of R\&D in technological original innovation. Proper financing methods and separate contract construction are necessary to technological original innovation, especially for those high-tech enterprises with problems as followed: information asymmetry, adverse selection and moral hazard (e.g. Landier, 2002; Winton and Yerramilli, 2004; Bettignies and Brander, 2007) [6-8]. The investment input and technological output of R\&D have positive effect on technological original innovation. Generally speaking, high input can increase output, but not scale up necessarily. Input and output is disproportionately related, and input may also have negative effect in some few cases. Different types of investors have different understanding for enterprise's technical original innovation ability, and can produce different effect (Long and Chang, 2008) [9].

The former research results did analysis on how to improve original innovation ability from knowledge innovation, industrial environment and capital input, and designed system to the development of original innovation. However, these researches didn't consider the inner factors of enterprise technological innovation, and didn't analyze the inner rules of the improvement of technological innovation ability. In fact, enterprises' inner factors of technological original innovation ability and its evolution mechanism is of great theoretical meanings for the cultivation and enhancement of enterprises' technological original innovation ability. Mutations theory by the French topologists Thom (1973) [10] is proposed to solve the discontinuous, divergent phenomenon, which has the potential to describe the multi-aspects evolution process of the nature, and can describe rules of movement or force under different states. The balance of natural forces mostly can take smooth surface to describe. Experiencing from balance to imbalance, enterprises technological original innovation sometimes encounter sections, then balance is broken and mutations of technological original innovation happens. Mutation theory can explain development process of the different stages from imitating type, fusion type to original type, and can explain enterprise technological original innovation evolution can be improved under the effect of institutional arrangements factor and its operation factors in order to improve enterprises performances. Thus, this paper tries to discuss enterprise technological original innovation evolution mechanism form the respect of enterprises inner ecosystem.

\section{Phase Analysis of Technology Original Innovation of Enterprises}

Hamilton et al. from the angle of technical management, think that the new technologies generating need to experience such a process: from scientific research revealing a kind of technical possibilities until this technology into the main commercialization market, and technical model is founded, which thinks that new technology extension primarily lies in the intersection between two regions of "form competition" and "the applied competition" (e.g. Hamilton and Mitchell, 2007; Bowman and Hurry, 1993) [11,12]. Technical innovation is that enterprise research and development of new products or new service in the process of using the original knowledge or creating knowledge, and is the process of technicalization of existing knowledge and creative knowledge, industrialization of the techbology and marketization of the product in order to obtain intellectual property with significant and comprehensive benefits (including technological benefits, economical benefits, social benefits, and environmental benefits). Therefore, knowledge and knowledge management in technology original innovation is the key factor for original innovation process. Technology original innovation have extremely high technology value, economic value and society value, but have extremely high risk and difficulty for enterprise technology innovation. So, for many enterprises, technological original innovation is not rely on original high R\&D funds or talents converging and development can achieve, but requires mastery technology the inherent law of original innovation of evolution.

In the original technological innovation model, new technique is compared with the traditional technology. It 
is a particular historical period of the category, in a continuous evolution and development state. New technology is a product of realization of certain historical period leading edge knowledge under specific conditions technology of the product. $T_{N}$ is the new technology of current period obtained by the enterprises from technicalizaiton of existing knowledge; $K_{0}$ is the existing knowledge of current period used by enterprises for innovation; $K_{N}$ is the new knowledge of c or using level and technology innovation value, the enterprises realize the origin urrent period for R\&D new technology. According to the knowledge creatingal innovation in technological innovation mainly has three evolutionary stages: imitation type of technology innovation, fusion of technical innovation and original technological innovation (Figure 1).

\subsection{Imitation Type Technology Innovation}

Imitation type enterprise technology innovation is the imitation or copy of industrial new technology with high economic value and technological value, which has similar or same functions with the existing technology or product under partly master or completely no access to the new technology. For example, in the pharmaceutical industry, generics means coping main molecular structure of the original medicine, but it is the same as original developed medicine in safety, efficacy, quality and indications etc. Imitation type technology innovation is the research and development of new products or new service on the basis of making use of knowledge to analyze the existing new technology enterprise. Therefore, imitation type technology innovation is the innovation of using the ready-made knowledge $\left(K_{0}\right)$, namely $T_{0}=$ $T\left(K_{0}\right)$; On this basis, the productization of technology and product marketization process respectively can be expressed as $P_{0}=P\left(T_{0}\right)$ and $M_{0}=M\left(P_{0}\right)$. Therefore, imitation type technology innovation can be expressed as:

$$
M_{0}=M\left(P_{0}\right)=M\left[P\left(T_{0}\right)\right]=M\left\{P\left[T\left(K_{0}\right)\right]\right\}
$$

Although the technology innovation mainly depends on the ready-made knowledge, this knowledge is relatively single, with no creation of new knowledge and low technology content, it is still a kind of technological progress for manufacturing enterprise but rather than just engaged in speaking, it is also, and of certain technical value and economic value.

\subsection{The Fusion of Technology Innovation}

Fusion of technological innovation is the process of enterprises comprehensively using various existing technology industry to develop new products or new service with high technology value, market value and economic value. From the viewpoint of knowledge management

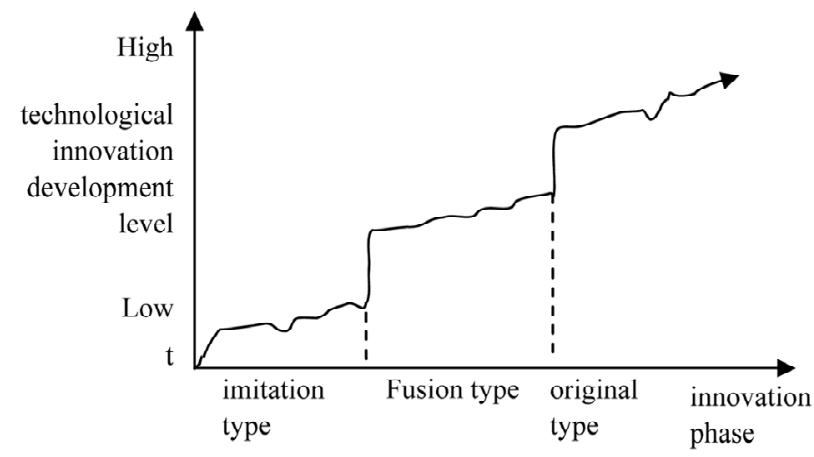

Figure 1. Enterprises original technological innovations phase.

perspective, the fusion of technology innovation primarily integrates and optimizes the ready-made knowledge and information to develop new technology. Compared with imitation type, although fusion of technology also make use of all kinds of ready-made knowledge ( $K_{O i}$ to create new technology, the knowledge range it integrates is wider and the difficulty of fusion is greater, and it realizes knowledge and information creative fusion. Meanwhile, without clear innovation goal, ready technical fusion type technology innovation lack of no ready technical can imitate, eventually developing a unprecedented new techniques and new products. After this period, fusion type of innovation optimize and integrate all kinds of ready-made knowledge $\left(K_{O i}\right)$ so as to realize industrialization. Therefore, fusion type of innovation can be expressed as followed:

$$
\begin{aligned}
& M_{N}=M\left(P_{N}\right)=M\left[P\left(T_{N}\right)\right]=M\left\{P\left[T\left(K_{O i}\right)\right]\right\} \\
& (i=1,2, \cdots, n)
\end{aligned}
$$

Therefore, enterprises have changed the technology or products during the process of fusion type of innovation, and new products in the whole function realized the qualitative leap. As a result, enterprises obtain independent intellectual property during the process of fusion. However, without creating new knowledge, it has essential difference from imitation types of innovation.

\subsection{Original Technological Innovations}

Original technological innovation means that enterprises have made unprecedented significant scientific development, technological advances or original leading technology, which has won great market value, economic value and social value within some aspects. From the knowledge management aspect, original technological innovation is not the application and integration of the readymade knowledge and information; it is of fundamental innovation within the basic research of technological innovation field or high-tech research field. Original innovation creates new knowledge and new theory $\left(K_{N}\right)$, 
and obtains completely new independent intellectual property. Original innovation has fundamental differences between imitation and fusion types of innovation. Original technological innovation can be expressed as:

$$
M_{N}=M\left(P_{N}\right)=M\left[P\left(T_{N}\right)\right]=M\left\{P\left[T\left(K_{N}\right)\right]\right\}
$$

\section{The Organization Collaborative Factor Analysis for Original Innovation}

\subsection{Organization Collaborative Factors for Enterprise Original Innovation}

Technical innovation is the process that the enterprise uses the original knowledge and transforms them into new technology. Many domestic researches show that the input and output of knowledge (i.e., creation of new technology) presents $S$ curve (Schilling, 2005) [13], namely that when the input of knowledge reached to a certain degree, new technology will be researched; while when exceeding that point of level, the possibility of researching new technology is decreasing and is approaching stable. $S$ curve is expressed by Logistic equation as following:

$$
T_{N}=\frac{\pi}{1+e^{a-b K}}
$$

In the equation, $T_{N}$ is developed new technology, $K$ is the knowledge invested or knowledge used. $a$ and $b$ is estimated coefficient, $\pi$ is the opportunity output of knowledge input or knowledge application when organized efficiently. Enterprises in technological innovation system arrangement and innovation management affect the $\pi$ size of Logistic equation, which is related to the possibility of original innovation of technology. As a result, the technology of original innovation organization collaborative factor mainly includes institutional arrangements factors and its operation factors: institutional arrangements factor is related to the original innovation of enterprise technology business purposes, management strategy, innovation standard, management organization and the provision of the respect such as business functions, and it is the rule to restraint and incentive primitive innovative personnel behavior, which can be expressed as " $s$ ". Organization operation factor is original innovation of technology enterprise planning, leading, organizing and controlling process, expressed as " $m$ ".

Hypothesis 1: institutional arrangements factor, organization operation factor and knowledge factor is key elements that affecting technical original innovation.

\subsection{Organization Collaborative of Enterprise Original Innovation}

Technology innovation activities are the nonlinear behaviors that original developers carry on knowledge and knowledge creation, and put the knowledge into new technology. It is the output of the synergy of institutional arrangements factor and organization operation factor: on one hand, technology original innovation is subject to institutional arrangements factor; on the other hand enterprises provide dynamic feedbacks according to the original innovation stage to increase conversion rate of knowledge to new technology. Thus, three core factors are related to enterprise original innovation: knowledgetechnology conversion $\left(r_{c}\right)$, institutional arrangements factor formation institutional constraints $(s)$ and innovation behavior feedback functions by organization operation factor $(m)$. It can be expressed by $\dot{m}=f\left(r_{c}, s, m, \varepsilon\right), r_{c}$ is the first derivative $T_{N}^{\prime}$ of successful new technology $T_{N}, \varepsilon$ stands for random disturbance action by other factors of technological original innovation.

In technological original innovation, the mutual coordination of these three factors consists of self-organization system, which forms a gradual to mutation research behavior based on knowledge - technology transformation. Because of the damping term by technological innovation, and because variables $\mathrm{m}$ has great influences on technological original innovation, by ignoring stochastic-disturbing factors, with cubical formal representation of the damping effect, $\dot{m}$ can be expressed by:

$$
\dot{m}=-4 m^{3}-2 r_{c} \cdot m-s
$$

Mutations theoretical research the phenomenon and law from a stable configuration warping to another kind of stable configuration. When using mathematical model to describe the continuity of a sudden interruption led to quantum action process, which possesses the feature of process continuity rather than results continuity, inner mechanism from stable state to another state is discovered. Just as the fore saying, technological original innovation is the continuous transformation from one stable stage to another stable stage. Thus, mutation theory is helpful to explain the inner mechanism of technological original innovation. This paper analyzes evolution mechanism of technological original innovation by mutation theory.

According to mutation theory, combined the function of $r_{c}, s$ and $m$ in technological original innovation, the organization collaborative function of enterprise technological original innovation can be expressed by $V(m)=m^{4}+r_{c} \cdot m^{2}+s \cdot m . m$ is state variable, and $r_{c}$ and $s$ are control variables. Thus, $V^{\prime}(m)$ can be expressed by $V^{\prime}(m)=4 m^{3}+2 r_{c} \cdot m+s=0$. According to cusps catastrophic model, a curved surface $P$ of three dimensional product space of $r_{c}-s-m, r_{c}, s$ and $m$ by one dimensional space by $V^{\prime}(m)$ ( $m$ axis), two dimensional variable space $\left(r_{c}-s\right)$, and therefore, a technological original innovation evolution picture can be concluded as followed (e.g. Ling, 1987; Thom, 1989; Liu and Gong, 1982) [14-16]. 
In Figure 2, (1) on the smooth surface $P$, from the original point $(0,0,0)$, within the half space $r_{c} \leq 0$, there is a trilobites fold area, and technology develops mutation. Upper lobe and lower lobe is the minimal point of potential function $V(m)$, and technological innovation are in stable state (or balance state). Among them, up lobe stands for technological innovation are in a high innovation stage, which is imitation technological innovation; while down lobe stands for technological are in low technological stage, which is original technological innovation stage. Middle lobe is the great point of potential function $V(m)$, which are in unstable stage, and is unreachable within the evolution of technological innovation. $\mathrm{BB}_{1} \mathrm{~B}_{2}$ is the division line between up lobe and down lobe; $\mathrm{BAC}$ is the division line between middle lobe and lower lobe. (2) $\mathrm{P}_{0}$ are the plane by control variable by $r_{c}$ and $\mathrm{m}$. Path a is the projection of $\mathrm{a}_{1}\left(\mathrm{~A}_{1} \mathrm{~A}_{2} \mathrm{~A}\right)$ and $a_{2}\left(B_{1} D H\right)$; while path $b$ is the projection $b_{1}(E F)$.

By differential the equation of $V^{\prime}(m)$, we can get $12 m^{2}+2 r_{c}=0$. Then calculate the simultaneous equations, we can get $r_{c}=-6 m^{2}$ and $s=8 m^{3}$. Then we can get $m= \pm \sqrt{\frac{-r_{c}}{6}}$ and $m^{3}=\frac{s}{g}$. Then put $m$ and $m^{3}$ into $V^{\prime}(m)=4 m^{3}+2 r_{c} \cdot m+s=0$, we can get $4 \times \frac{s}{g}+2 r_{c} \cdot\left( \pm \sqrt{\frac{-r_{c}}{6}}\right)+s=0$, that is $8 r_{c}^{3}+27 s^{2}=0$. The subset obtained by the equation stands for projection of $\mathrm{BB}_{1} \mathrm{~B}_{2}$ and $\mathrm{BAC}$ on the surface of $P$, that is curve $\mathrm{XY}$ and curve $\mathrm{XZ}$.

Curve $\mathrm{XY}$ and curve $\mathrm{XZ}$ are the division lines of technological innovation to create mutation. (1) When the change of control variable $r_{c}$ and $m$ doesn't reach to these two lines, the technological innovation of enterprises only has quantities changes rather than qualitative changes. (2) When control variable $r_{c}$ and $m$ reach to these two lines, the technological innovation has qualitative changes, which is a mutation changes. Meanwhile, from Figure 2, the evolution of technological original innovation has hysterics. For example, when technological innovation positively evolutes along with path a, that is $A_{1}$ evolutes toward to A along with path $a_{1}$, it first reaches curve $\mathrm{XY}$, but technological mutation doesn't happen; only when it reaches curve $\mathrm{XY}$, may new mutation happen. That is the hysteretic nature of technological original innovation.

\section{Evolution Mechanism of Technological Original Innovation}

According to the enterprise technological original innovation evolution phrases and mutation theory, combined with organization collaborative factors and its collabora-

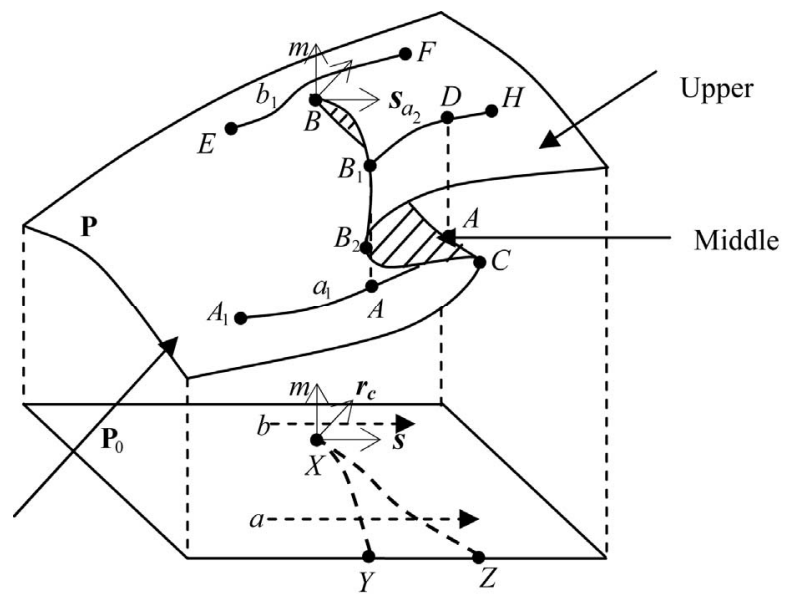

Figure 2. The evolution chart of enterprise technological original innovation.

tive mechanism, authors did analysis on the technological original innovation from imitation innovation, fusion innovation to original innovation, and discover inner laws of technological original innovation.

\subsection{Imitation Type of Technological Innovation Evolution}

In Figure 2, when enterprises are in low knowledge input level, and with low knowledge - technology conversion rate $r_{c} \leq 0$, which remains stable, the feedback function $(m)$ by knowledge- technology conversion rate $\left(r_{c}\right)$, regulation restriction by institutional arrangement factors $(s)$ and organizational operating factors $(m)$ moves toward A along with curve $a_{1}$. With the increasing of the institutional arrangement factors $s$, the feedback function $(m)$ by organizational operating factors will continuously increase. Then, technological innovation evolution path presents itself as a projection of curve $S$, that is the $\mathrm{A}_{1} \mathrm{~A}_{2} \mathrm{~A}$ in Figure 3. Under this circumstances, the technological innovation is still imitation stage, and still remain changes, which means the imitation innovation level of enterprises is increasing, but no qualitative changes happens, and original technological changes doesn't happen.

Hypothesis 2: when $r_{c} \leq 0$, institutional arrangement factors can play a more important role of imitation innovation, but mutation can be realized.

\subsection{Original Technological Innovation Evolution}

In Figure 2, when enterprises are in high knowledge input level, and with high knowledge - technology conversion rate $r_{c} \geq 1$, the feedback function $(m)$ by knowledge - technology conversion rate $\left(r_{c}\right)$, regulation restriction by institutional arrangement factors $(s)$ and organizational operating factors $(\mathrm{m})$ moves toward A along with curve $a_{1}$ and surpass A. Under the fast function of the feedback function $(m)$ by institutional arrangement 


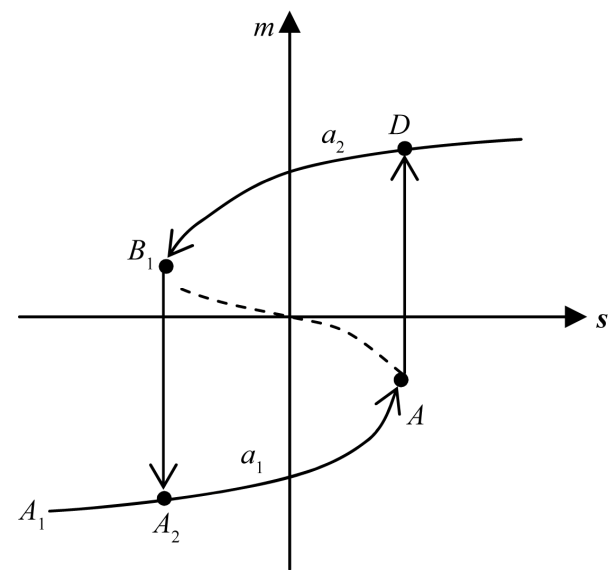

Figure 3. Enterprises technological innovation gradual change and mutation chart.

factors $(s)$ and organizational operating factors, the A point, which is on the edge of enterprises technological curve $\mathrm{BAC}$, has a mutation to point $\mathrm{E}$, it snap back from the down lobe to up lobe, and the evolution path presents a projection of $\mathrm{S}$ curve on variables $m-s$, that is the $\mathrm{A}_{2} \mathrm{AD}$ part in Figure 3. Under these circumstances, enterprises technological innovation lies on the basis of creating new knowledge, new technology is created by new knowledge, and mutation from imitation innovation to original innovation is realized.

Hypothesis 3: when $r_{c} \geq 1$, organizational arrangement factor and organization operating factor can improve the technological innovation level, and mutation to original innovation may be realized.

\subsection{Fusion Technological Innovation Evolution}

When knowledge - technology conversion rate $r_{c}>0$ and $r_{c}<1$, the feedback function by knowledge - technology conversion rate $\left(r_{c}\right)$, regulation restriction by institutional arrangement factors $(s)$ and organizational operating factors will move from $\mathrm{E}$ to $\mathrm{F}$ along with curve $\mathrm{b}_{1}$. Technological innovation evolution path presents another projection of S curve on variable $m-s$, that is the EF part in Figure 4. Under this circumstances, on the basis of optimizing and integrating all kinds of ready-made knowledge, enterprise technological innovation finish the R\& D within the continuous gradually changed process. Although no new knowledge is created and used, the R\&D of new technology is completed, qualitative changes is accomplished during the technological innovation process.

Hypothesis 4: when $r_{c}>0$ and $r_{c}<1$, under the mutual function of organization arrangement factor and organization operating factor, enterprises realizes technological innovation through integrating all kinds of ready-made knowledge, and fusion innovation is accomplished during the process of gradual change.

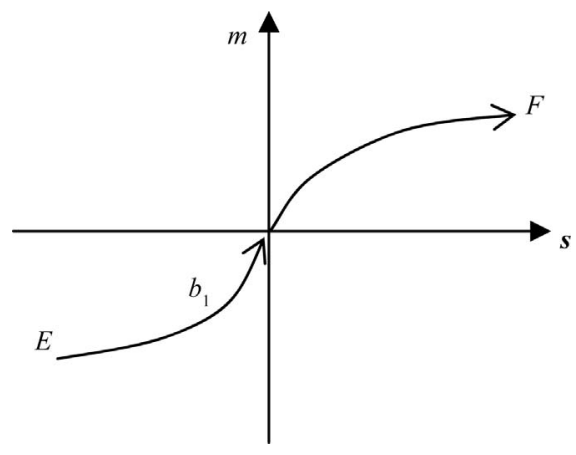

Figure 4. Enterprise fusion type of innovation evolution chart.

To sum up, in order to realize original innovation, enterprises can achieve its goal by mutation form imitation type of innovation, or by gradual change from fusion innovation.

\section{Empirical Analysis}

\subsection{Investigation Sample Design for Empirical Analysis}

In order to verify the rationality and scientific nature of enterprise original innovation, the author mainly select typical representative enterprise with three different stages in technology innovation, in China Yangtze river delta region of Shanghai, Zhejiang and Jiangsu provinces. A sample mainly covers more than 10 industries such as medicine, energy, electronics, IT and so on, and includes 101 enterprises totally. Surveys were issuing 240 copies of questionnaires, and actual recycling 232 questionaires, among which the effective questionnaire is 223 copies and 40,052 effective data, are acquired. Among effective samples, $41 \%$ are in imitation technological innovation, $35 \%$ are in fusion technological innovation, while $24 \%$ belongs to original innovation.

\subsection{Investigation Tools Design}

In empirical investigation, authors mainly make use of Likert scale as investigation tools. During the design of Likert scale, group discussion method and individual depth interview method were carried out in 6 companies by 32 person-times of informal survey. 127 statements relevant to enterprise technology original innovation of all aspects were collected. Those statements were classified and arranged, and 86 statements of technological innovation were obtained. Second, using " $1,2,3,4,5$ " to stand for from "totally disapproval" to "quite agree", by using 5 scales, 23 people were selected as pre-subjects to do the questionnaires. Personal attitude total mark was obtained. And subjects were grouped into two parts: high-mark group and low-mark group. High-mark group hold positive opinions, with 40 statements and low-mark 
groups hold negative opinions, with 46 statements. Finally, 20 from high-mark group and 23 from low-mark group were selected. By using Likert 11 scales, with "0 10 " stands for "extremely in favor of" to "very approve", Likert scale for the investigation was obtained.

\subsection{Reliability Analysis of Investigation Scale}

To test the scale reliability of Likert scale, the author first invited 26 technical researchers and development personnel to do questionnaire survey, and then try again to do reliability analysis according to the survey results. In the study, this paper uses SPSS11.5 software to do Reliability Analysis. During reliability analysis, item-total correlation of one variable is 0.2661 , lower than 0.3 , which is eliminated. Then reliability analysis is done again. Another variable, whose item-total correlation is 0.2318 , is eliminated. Then 41 variables are left, whose item-total correlation are above 0.39 . Cronbach's $\alpha$ of the total table is 0.9761 (Table 1), which is higher than the standard of 0.9771 . The reliability of this investigation is comparatively high.

\subsection{Empirical Analysis for Hypothesis 1}

Based on each variable, son variable and related original data, we did factor analysis. Factor Analysis mainly finds out public factor of each variable through variables dimension reduction of the basic factors that can reflect technological original innovation. Screed Plot is made for factor analysis (Figure 5). In Figure 5, abscissa denotes factor number, while y-coordinate stands for the corresponding value of each factor. Then draw dot according to them, and connect line, then scree plot can be obtained. The importance of each factor can be reflected from the slop of the lines. The steeper the line is, the more importance the factor is. Thus, factor 1 , factor 2 and factor 3 are the three leading factors (institutional arrangement factor, organization operating factor and knowledge factor), and other factors are secondary factor.

Table 2 shows KMO inspection and Bartlett ball degrees inspection results for factor analysis. From Table 2, $\mathrm{KMO}$ results is 0.857 , very close to 1 , which means the sample data is large enough. Bartlett ball degrees inspection results shows that Approx. Chi-Square is 3800.554, df is 861 , and inspection of significant probability is 0.000 . Thus, through the significant test, four public factors obtained from factor analysis are effective; hypothesis 1 is established.

\subsection{Empirical Analysis for Hypothesis 2}

Input and output of knowledge presents $\mathrm{S}$ curve (namely logistic equations). Though Binary Logistic Regression model, the evolution mechanism for imitation type of innovation is tested. With low knowledge input level and
Table 1. Reliability analysis of the investigation table.

\begin{tabular}{|c|c|c|c|c|c|c|}
\hline & Mean & Minimun & Maximum & Range & Max/Min & Variance \\
\hline Item Means & 6.0840 & 4.5237 & 7.4429 & 2.9192 & 21.6453 & 0.4220 \\
\hline $\begin{array}{l}\text { Item } \\
\text { Variances }\end{array}$ & 6.0259 & 3.3706 & 9.9090 & 6.5383 & 32.9398 & 3.2570 \\
\hline $\begin{array}{l}\text { Inter-item } \\
\text { Covariances }\end{array}$ & 3.0090 & 0.0409 & 7.8943 & 7.8534 & 193.2480 & 1.4250 \\
\hline $\begin{array}{l}\text { Inter-item } \\
\text { Correlations }\end{array}$ & 0.5095 & 0.0058 & 0.9143 & 0.9085 & 158.8413 & 0.0281 \\
\hline \multicolumn{2}{|c|}{ Reliability Coefficients } & ts & ns & & & \\
\hline \multicolumn{2}{|c|}{ Alpha $=0.9761$} & Sta & Idardized it & tem alph & $\mathrm{a}=0.9771$ & \\
\hline
\end{tabular}

Table 2. KMO and Bartlett's test of factor analysis.

\begin{tabular}{lcc}
\hline Kaiser-Meyer-Olkin Measure of Sampling Adequacy. & 0.857 \\
\hline \multirow{3}{*}{ Bartlett's Test of Sphericity } & Approx. Chi-Square & 3800.554 \\
& df & 861 \\
& Sig. & 0.000 \\
\hline
\end{tabular}

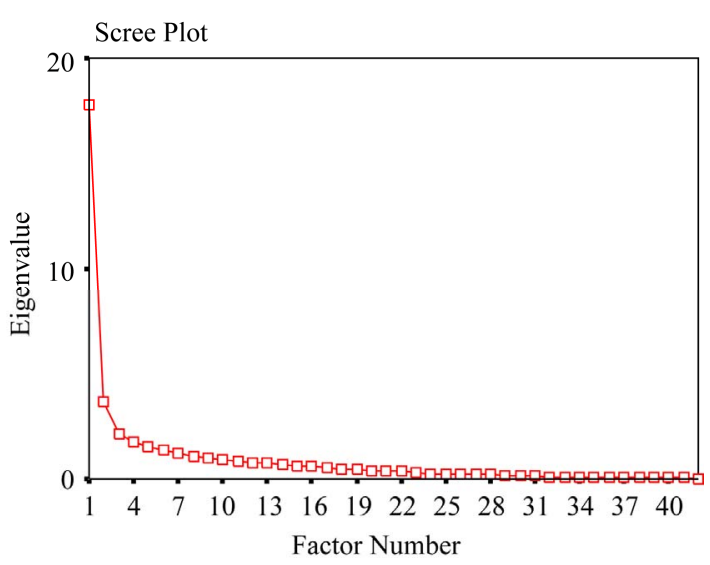

Figure 5. Scree plot of factor analysis.

$r_{c} \leq 0$, the logistic regression results between imitation technological innovation and the feedback function $(m)$ of institutional arrangement factor $(s)$ and organization operating factor are showed in Tables 3 and 4.

From Table 3, the Sig. value of $\mathrm{m}$ and $r_{c}$ are both larger than 0.05 , without any statistic significance; while regulation restraints $(s)$ by institution arrangement factor and constant are both have significant statistic meanings. Meanwhile, Sig. value of Hosmer and Lemeshow Test in Table 4 is apparently lower than 0.05 , which means that with low knowledge input level and $r_{c} \leq 0$, feedback function of organization operating factor is comparatively lower, and regulation restraints of institution arrangements factor has greater effect on imitation type of innovation. The model prediction accuracy reaches $87.1 \%$, which shows hypothesis 2 is established.

\subsection{Empirical Analysis for Hypothesis 3}

Though Binary Logistic Regression model, the evolution 
Table 3. Variables in the equation.

\begin{tabular}{rccccccc}
\hline & & B & S.E. & Wald & df & Sig. & $\operatorname{Exp(B)}$ \\
\hline $\begin{array}{c}\text { Step } \\
\text { 1(a) }\end{array}$ & $s$ & -1.421 & 0.354 & 16.128 & 1 & 0.000 & 0.241 \\
& $m$ & -0.339 & 0.323 & 1.096 & 1 & 0.295 & 0.713 \\
& $r_{c}$ & -0.192 & 0.892 & 0.046 & 1 & 0.830 & 0.825 \\
& Constant & 10.743 & 2.579 & 17.356 & 1 & 0.000 & 46314.726 \\
\hline
\end{tabular}

a Variable(s) entered on step 1: $s, m, r_{c}$.

Table 4. Hosmer and lemeshow test.

\begin{tabular}{cccc}
\hline Step & Chi-square & df & Sig. \\
\hline 1 & 19.321 & 8 & 0.013 \\
\hline
\end{tabular}

mechanism for original type of innovation is tested. When the knowledge input level is high, and $r_{c} \geq 1$, the results are showed in Tables $\mathbf{5}$ and $\mathbf{6}$.

From Table 5, Sig. value of $m, s, r_{c}$ and constant is lower than 0.05 , which is of significant statistic meanings. Meanwhile, Sig. value of Hosmer and Lemeshow Test in Table 6 is apparently lower than 0.05 , which means this model is of significant statistic meanings. The model prediction accuracy reached $88.1 \%$, which shows hypothesis 3 is established.

\subsection{Empirical Analysis for Hypothesis 4}

Though Binary Logistic Regression model, the evolution mechanism for fusion type of innovation is tested. When $r_{c}>0$ and $r_{c}<1$, the results are showed in Tables 7 and 8.

From Table 7, we can see that Sig. value of $s, r_{c}$ and constant is larger than 0.05 , which lack of statistic significance; while the Sig. value feedback functions of organization operation factor $(m)$ is lower than 0.05 , with significant statistic meanings. Meanwhile, Sig. value of Hosmer and Lemeshow Test in Table 6 (0.001) is lower than 0.05 , which shows that this model is of significant statistic meanings. When $r_{c}>0$ and $r_{c}<1$, that is knowledge - technology conversion rate is high, the feedback function $(m)$ of organization operation factor has greater effect on fusion type of innovation. The model prediction accuracy reached $85.3 \%$. It shows that the feedback function $(m)$ of organization operation factor is more important than that of institution restraint $(s)$ of institution arrangements factor. Thus, hypothesis 4 should be moderated. "Under the mutual function of institution arrangement factor and organization operation factor" should be changed into "under the function of organization operation."

\section{Conclusions}

Technological original innovation is that enterprises re-
Table 5. Variables in the equation.

\begin{tabular}{|c|c|c|c|c|c|c|c|}
\hline & & B & S.E. & Wald & $\mathrm{df}$ & Sig. & $\operatorname{Exp}(B)$ \\
\hline \multirow[t]{4}{*}{ Step 1} & $s$ & 1.336 & 0.357 & 14.017 & 1 & 0.000 & 3.804 \\
\hline & $m$ & 0.640 & 0.337 & 3.601 & 1 & 0.048 & 1.896 \\
\hline & $r_{c}$ & 0.353 & 0.388 & 3.105 & 1 & 0.046 & 1.823 \\
\hline & Constant & -13.410 & 3.114 & 18.540 & 1 & 0.000 & 0.000 \\
\hline
\end{tabular}

Table 6. Hosmer and lemeshow test.

\begin{tabular}{cccc}
\hline Step & Chi-square & df & Sig. \\
\hline 1 & 25.194 & 8 & 0.001 \\
\hline
\end{tabular}

Table 7. Variables in the equation.

\begin{tabular}{cccccccc}
\hline & & B & S.E. & Wald & df & Sig. & $\operatorname{Exp(B)}$ \\
\hline Step 1 & $s$ & 0.299 & 0.210 & 2.042 & 1 & 0.153 & 1.349 \\
& $m$ & -0.506 & 0.247 & 4.220 & 1 & 0.040 & 0.603 \\
& $r_{c}$ & 0.268 & 0.698 & 0.148 & 1 & 0.701 & 1.308 \\
& Constant & 1.215 & 1.125 & 1.165 & 1 & 0.280 & 3.369 \\
\hline
\end{tabular}

Table 8. Hosmer and lemeshow test.

\begin{tabular}{cccc}
\hline Step & Chi-square & df & Sig. \\
\hline 1 & 7.402 & 8 & 0.049 \\
\hline
\end{tabular}

search and develops new products or new technology by the aid of using or creating knowledge. It is the technicalization of knowledge, productization of technology and marketization of product, which finally obtain the independent intellectual property of significant comprehensive benefits (including technological benefits, economic benefits, social benefits and environmental benefits). Before the realization of technological original innovation, imitation innovation and fusion innovation should be realized before.

Technological original innovation is the process of enterprises making use of knowledge to create new technology. The input and output of knowledge presents $\mathrm{S}$ curve. Logistics equation is used to show the evolution mechanism of technological original innovation. Mutation theory is used to analyze the evolution mechanism of technological original innovation. 1) when $r_{c} \leq 0$, institutional arrangement factor has greater effect on imitation innovation, but mutation of technological innovation level can not be realized; 2) when $r_{c} \geq 1$, institutional arrangement factor and organization operation factor can promote technological innovation level, mutation can be achieved, and original innovation can be obtained; 3) when $r_{c}>0$ and $r_{c}<1$, under the organization operation factor, enterprises achieve fusion type of innovation through gradual change by integrating all kinds of ready-made knowledge. Through the investigation data of enterprise from China's Yangtze River delta region, this paper put 
forward hypothesis and verify the scientific nature and rationality of the evolution of technological original innovation.

\section{Acknowledgements}

This research was supported by the National Science Foundation under the Grant 71031003; The national ministry of education in humanities and social science research project (10YJC630116); 2009 Jiangsu university philosophy social sciences funded projects (09SJB630041).

\section{REFERENCES}

[1] S. Haider, "Organizational Knowledge Gaps: Concept and Implications," Druid Summer Conference, Denmark, 12-14 June 2003, pp. 1-24.

[2] E. Kirner, S. Kinkel and A. Jaeger, "Innovation Paths and the Innovation Performance of Low-Technology FirmsAn Empirical Analysis of German Industry," Research Policy, Vol. 38, No. 3, 2009, pp. 447-458. doi:10.1016/j.respol.2008.10.011

[3] A. Malmberg, "The Elusive Concept of Localization Economies: Towards a Knowledge-Based Theory of Spatial Clustering," AAG Annual Conference, New York, 27 February-3 March 2001, pp. 429-449.

[4] C. Nunzia, "Innovation Processes within Geographical Clusters: A Cognitive Approach," Technovation, Vol. 24, No. 1, 2004, pp. 17-28. doi:10.1016/S0166-4972(02)00046-9

[5] H. Tsai and J. C. Wang, "External Technology Sourcing and Innovation Performance in LMT Sectors: An Analysis Based on the Taiwanese Technological Innovation Survey," Research Policy, Vol. 38, No. 3, 2009, pp. 518-526. doi:10.1016/i.respol.2008.10.007
[6] A. Landier, "Start-Up Financing: From Banks to Venture Capital," Working Paper, University of Chicago, Chicago, 2002.

[7] A. Winton and V. Yerramilli, "A Model of Entrepreneurial Finance," Working Paper, University of Minnesota, Minneapolis, 2004.

[8] J. E. Bettignies and J. Brander, "Financing Entrepreneurship: Bank Finance Versus Venture Capital," Journal of Business Venturing, Vol. 22, No. 6, 2007, pp. 808-832. doi:10.1016/j.jbusvent.2006.07.005

[9] Y. Long and J. H. Chang, "A Study on the Relationships among Types of Innovation, Financing Choice and Market Strategy in Young High-Tech Firm," Science of Science and Management of $S . \& T$, Vol. 10, No. 1, 2008, pp. 70-74.

[10] R. Thom, "Structural Stability and Morphogenesis, English Translation of Stabilite Structurelle et Morphogenese," W. A. Benjamin, Inc., New York, 1973.

[11] E. H. Bowman and D. Hurry, "Strategy through the Options Lens: An Integrated View of Resource Investments and the Incremental-Choice Process," Academy of Management Review, Vol. 18, No. 4, 1993, pp. 760-782.

[12] W. F. Hamilton and G. R. Mitchell, "Managing R\&D as a Strategic Option," Research \& Technology Management, Vol. 50, No. 2, 2007, pp. 41-50.

[13] M. A. Schilling, "Strategic Management of Technological Innovation," Tsinghua University Press, Beijing, 2005.

[14] F. H. Ling, "Mutation Theory and Its Applications," Shanghai Jiao Tong University Press, Shanghai, 1987.

[15] R. Thom, "Mutation Theory: Ideas and Applications," Shanghai Translation Publishing House, Shanghai, 1989.

[16] J. M. Liu and C. D. Gong, "A Justification for the Scaling of the Thom-System," Communication of Theoretical Physics (China), Vol. 16, No. 1, 1982, pp. 405-412. 